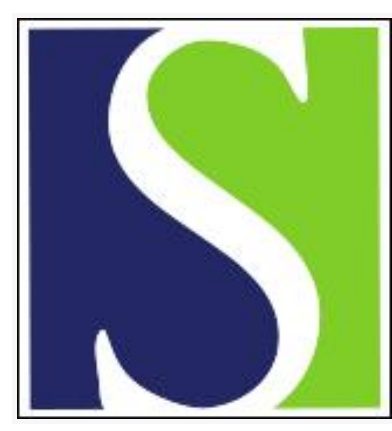

Scand J Work Environ Health 1987;13(4):279-283

https://doi.org/10.5271/sjweh.2050

Issue date: Aug 1987

Sensorineural stages of the hand-arm vibration syndrome.

by Brammer AJ, Taylor W, Lundborg G

Affiliation: Division of Physics, National Research Council of Canada, Ottawa, Ontario.

This article in PubMed: www.ncbi.nlm.nih.gov/pubmed/3324308 


\title{
Sensorineural stages of the hand-arm vibration syndrome
}

\author{
by Anthony J Brammer, PhD, ${ }^{1}$ William Taylor, $\mathrm{DSc}, \mathrm{MD}^{2}{ }^{2}$ Göran Lundborg, $\mathrm{MD}^{3}$
}

\begin{abstract}
BRAMMER AJ, TAYLOR W, LUNDBORG G. Sensorineural stages of the hand-arm vibration syndrome. Scand J Work Environ Health 13 (1987) 279-283. Recent work has shown that the vascular signs and neurological symptoms commonly associated with exposure of the hand to vibration may develop independently. A classification for the neurological component of the hand-arm vibration syndrome has been developed for those symptoms dominated by sensory afferent involvement, based on the results of objective tests on 634 hands. The first symptomatic stage (1SN) consists essentially of episodic finger numbness with or without tingling, the second involves, in addition, reduced sensory perception (2SN), while the most severe stage (3SN) focuses on reduced tactile discrimination and/or manipulative dexterity. Consistent implementation of this classification by means of objective tests requires one, or more, precise, quantitative measure of peripheral somatosensory dysfunction, in addition to the traditional neurological tests (fine touch, pain, and temperature). Measurements of tactile function by means of esthesiometry or vibrotactile perception appear suited to this purpose. A procedure for staging individual hands may then be based on combining numerical scores assigned to the results of the traditional neurological tests and, additionally, esthesiometer and/or vibrotactile perception thresholds.
\end{abstract}

Key terms: esthesiometer, manipulative dexterity, numbness, objective tests, tactile discrimination, vibrotactile perception.

A pattern of peripheral vascular, neurological, and musculoskeletal signs and symptoms has become associated with repeated exposure of the hand to vibration in industry. The most common of these signs and symptoms have been well summarized, together with the expected impact on a person's social and work activities, in the widely used Taylor-Pelmear stages of vibration-induced white finger (VWF), shown in table 1 (20). This classification focuses on the episodic vasospasms characteristically reported by operators of power tools or industrial processes in which intense vibration is transmitted to the hands. It also includes three preliminary stages that do not involve finger blanching but, rather, involve episodic tingling and/or numbness of the digits (stages $0_{\mathrm{T}}, 0_{\mathrm{N}}$, and $0_{\mathrm{TN}}$ ). By implication, these early symptoms and much of the reported interference with activities at work in severe cases, which may be associated with reduced manual dexterity (1), are caused at least in part by peripheral neurological or neuromuscular dysfunction (4).

The Taylor-Pelmear classification was based on clinical experience and reports from vibration-exposed workers. Evidence from several sources now suggests that the various components of the syndrome may develop independently $(3,10,18)$. Thus separate classifications of peripheral vascular, neurological, and, per-

1 Division of Physics, National Research Council of Canada, Ottawa, Canada.

2 Department of Community Medicine, University of Dundee, Dundee, Scotland.

3 Department of Hand Surgery, University of Lund, Malmö, Sweden.

Reprint requests to: Dr AJ Brammer, Division of Physics, National Research Council of Canada, Montreal Road, Ottawa, Ontario K1A 0R6, Canada. haps, musculoskeletal disturbances may be required, ultimately supported by appropriate objective tests to identify persons at risk and to evaluate the severity of each condition. Furthermore, the recognition of significant neurological involvement in the syndrome requires a differential diagnosis of vibration-exposed workers to include causes of peripheral neuropathy and polyneuropathy (13).

The purpose of this paper is to propose a classification for the sensorineural symptoms commonly reported in vibration-exposed hands. The peripheral sensory involvement is first established by reference to the results of objective sensory tests performed on workers who have been carefully screened to exclude other causes of similar symptoms. Based on this analysis,

Table 1. Taylor-Pelmear stages of vibration-induced white finger (taken from reference 20 with permission of $W$ Taylor and PL Pelmear).

\begin{tabular}{|c|c|c|}
\hline Stage & Condition of digits & Work and social interference \\
\hline 0 & $\begin{array}{l}\text { Vibration exposed but no } \\
\text { signs or symptoms }\end{array}$ & No complaints \\
\hline $0_{\mathrm{T}}$ & Intermittent tingling & No interference with activities \\
\hline $0_{N}$ & Intermittent numbness & No interference with activities \\
\hline 1 & $\begin{array}{l}\text { Blanching of one or more } \\
\text { fingertips with or without } \\
\text { tingling or numbness }\end{array}$ & No interference with activities \\
\hline 2 & $\begin{array}{l}\text { Blanching of one or more } \\
\text { fingers with numbness, } \\
\text { usually confined to winter }\end{array}$ & $\begin{array}{l}\text { Slight interference with } \\
\text { home and social activities; } \\
\text { no interference at work }\end{array}$ \\
\hline 3 & $\begin{array}{l}\text { Extensive blanching, } \\
\text { frequent episodes summer } \\
\text { and winter }\end{array}$ & $\begin{array}{l}\text { Definite interference at work, } \\
\text { at home and with social } \\
\text { activities; restriction of } \\
\text { hobbies }\end{array}$ \\
\hline 4 & Same as 3 & $\begin{array}{l}\text { Same as } 3 \text {, but occupation } \\
\text { changed to avoid further } \\
\text { vibration exposure }\end{array}$ \\
\hline
\end{tabular}

a Note: $0_{\mathrm{TN}}=0_{\mathrm{T}}+0_{\mathrm{N}}$. 
four sensorineural stages are proposed. The relationship between these stages and a previous attempt to develop a neurological classification is then examined (5), together with their implementation in individual cases by means of both traditional and improved objective tests.

The symptoms associated with each sensorineural stage were discussed at a special session of the Stockholm workshop on symptomatology and diagnostic methods for the hand-arm vibration syndrome, at which time a separate classification of the vascular signs was undertaken (8).

\section{Peripheral sensory involvement}

The percentages of hands found to possess normal responses to light touch, pain, and thermal stimuli in the most carefully controlled epidemiologic study of vibration-exposed workers known to the authors are shown in table 2 (identified by superscript a) (21). The results of these traditional sensory tests have been expressed by Taylor-Pelmear stage of VWF (table 1) after the exclusion of data from persons with evidence of disease unrelated to vibration exposure at work, or other confounding factors (as established by a questionnaire and two independent medical examinations). In view of the few advanced cases and limited range of power tools used in most population groups (in reference 21 - pneumatic chipping hammers and handheld grinders), it was considered necessary to confirm these results with additional information from other sources. Accordingly, comparable results obtained from severe cases seeking compensation (19), and from symptomatic workers in a pilot study (3), are included in table 2 (identified by superscript $b$ ). These results, though obtained separately, employed clinical procedures identical to those of the original study and were available to us for further processing. The workers in this group had operated either chain saws, pedestal

Table 2. Percentage of hands with normal responses to light touch, pain, and temperature according to the Taylor-Pelmear stage of vibration-induced white finger.

\begin{tabular}{lrrrr}
\hline $\begin{array}{l}\text { Taylor-Pelmear } \\
\text { stage }\end{array}$ & $\begin{array}{c}\text { Number } \\
\text { of hands }\end{array}$ & $\begin{array}{c}\text { Light } \\
\text { touch }\end{array}$ & Pain & $\begin{array}{l}\text { Tem- } \\
\text { pera- } \\
\text { ture }\end{array}$ \\
\hline Referents & $122^{\mathrm{a}}$ & 100 & 100 & 98 \\
0 & $84^{\mathrm{a}}$ & 81 & 86 & 79 \\
& $4^{\mathrm{b}}$ & 100 & 100 & 100 \\
$0_{\mathrm{T}}$ & $36^{\mathrm{a}}$ & 89 & 67 & 72 \\
$0_{\mathrm{N}}$ & $36^{\mathrm{a}}$ & 72 & 50 & 50 \\
$0_{\mathrm{TN}}$ & $72^{\mathrm{a}}$ & 44 & 42 & 44 \\
& $4^{\mathrm{b}}$ & 50 & 50 & 0 \\
& $64^{\mathrm{a}}$ & 72 & 38 & 16 \\
& $6^{\mathrm{b}}$ & 83 & 50 & 50 \\
2 & $62^{\mathrm{a}}$ & 42 & 29 & 23 \\
& $38^{\mathrm{b}}$ & 45 & 18 & 13 \\
$3+4$ & $18^{\mathrm{a}}$ & 22 & 11 & 0 \\
& $88^{\mathrm{b}}$ & 11 & 0 & 0 \\
\hline
\end{tabular}

a Data from reference 21.

b Data from reference 3 and 19 . grinders, rock drills, or road breakers. As an additional precaution to avoid cases involving nerve entrapment (particularly carpal tunnel syndrome), all hands for which sensory data from digits 5 and 3 (or 5 and 2) differed significantly were excluded from group b (2).

Inspection of table 2 reveals that, when data are available from sources $a$ and $b$, the percentages of normal responses differ by less than $20 \%$, with the exception of the thermal stimulus at stages $0,0_{\mathrm{TN}}$, and 1 . This finding is believed to reflect the small number of subjects in group b and the inherently insensitive method of measurement (response of fingertips to a surface maintained at $40^{\circ} \mathrm{C}$ ). When taken together and compared with the results of referents, the data for light touch, pain, and temperature all display a systematic reduction in normal responses with increasing stage of VWF involving finger blanching (ie, stages 1 , 2,3 , and 4). This complete rank correlation between Taylor-Pelmear stage and decreasing peripheral sensory function, as detected by traditional neurological tests, is somewhat less evident when data from stages $0_{\mathrm{T}}, 0_{\mathrm{N}}$, and $0_{\mathrm{TN}}$ are included prior to stage 1 . Nevertheless, the Spearman rank correlation coefficients (r) between symptomatic stages, as listed by the presumed increase in severity in table 1 , and the data in table 2 for light touch $(r=0.89)$, pain $(r=1.00)$, and temperature $(r=0.96)$ remain statistically significant $(\mathrm{P}<0.01$ ), indicating a continuing though weakened association between sensory symptoms and this grouping of workers.

It is thus evident that with careful control of confounding factors a common pattern of sensory loss can be identified in the hands of persons regularly exposed to vibration. Futhermore, these data, from 634 hands, imply that the severity of sensorineural changes in individual hands may be better classified without reference to the presence or absence of episodic vasospasms.

\section{Proposed sensorineural stages}

Results from several sources suggest that the various components of the hand-arm vibration syndrome may develop independently, though typically concurrently. These sources include longitudinal epidemiologic studies of vibration-exposed populations (18), individual cases with severe sensorineural changes at the fingertip but no vasospastic involvement (3), and statistical analyses of multiple tests of peripheral vascular, neurological, and neuromuscular function (10). These observations, as well as the analysis of the previous section, imply that separate classifications of at least the sensorineural and vascular components are warranted, though the latter demonstrates the close association, on a group basis, between the frequency of sensory changes and the existing Taylor-Pelmear stages. In addition to the neurological symptoms explicitly contained in table 1 , Taylor \& Pelmear drew attention to impaired touch and temperature sensation 
in advanced cases, and the "loss of (manual) dexterity and inability to do fine work" (20).

Accordingly, three progressive, symptomatic stages are proposed for classifying clinically the sensorineural component of the hand-arm vibration syndrome. The dominant symptoms taken to define each stage are listed in table 3 , together with an initial symptomfree stage to differentiate vibration-exposed workers from other persons (stage OSN). The first symptomatic stage (1SN), consisting primarily of reports of numb fingers, may be difficult to verify by objective tests. It is evident from the significant change in normal responses to light touch, pain, and temperature between the extremes of the Taylor-Pelmear classification (namely, from, typically, $91 \%$ normal in stage 0 , to $7 \%$ normal in stages $3+4-$ see table 2 ) that sensory perception is reduced at some stage in the development of VWF. This symptom, together with episodic or persistent numbness, is taken to define stage $2 \mathrm{SN}$. In the most advanced stage (3SN), sensory perception is sufficiently degraded to influence the performance of fine tasks involving tactile discrimination (ie, identification of surface features or texture) and/or manipulative dexterity. The inclusion of fine manipulative tasks is considered justified by recent work in which the precision gripping of objects between the tips of the fingers and thumb has been found to depend primarily on mechanoreceptor rather than neuromuscular function (12).

The classification, which is applicable to individual hands, thus includes only those symptoms believed to be dominated by cutaneous afferent involvement. Hence total hand-grip strength and the so-called neurovegetative effects (palmar sweating, vertigo, etc) have been excluded (9).

\section{Discussion and interpretation}

There have been several classifications proposed for various combinations of signs and symptoms occurring in the hand-arm vibration syndrome. (See, for example, reference 9.) However, only Brammer et al (5) have attempted to classify the vascular signs and neurological symptoms into separate, but parallel, stages, identified by $\mathrm{V}$ and $\mathrm{N}$, respectively. The latter were based entirely on degraded tactile sensation because of its close association with impaired hand function (6). The symptomatic neurological stages suggested by Brammer et al (5) are: stage $1 \mathrm{~N}$ (intermittent tingling and/or numbness); stage $2 \mathrm{~N}$ (intermittent numbness and reduced tactile perception); and stage $3 \mathrm{~N}$ (degraded tactile resolution and numbness). The essential difference between the stages of Brammer et al (5) and the present neurological classification is thus the inclusion, first in stage $2 \mathrm{SN}$, of functional changes in thermoreceptors and nociceptors and/or their associated nerve fibers. Changes in these somatosensory subsystems can be seen from table 2 to occur more
Table 3. Proposed sensorineural stages of the hand-arm vibration syndrome.

\begin{tabular}{ll}
\hline Stage $^{a}$ & Symptoms \\
\hline OSN & Exposed to vibration but no symptoms \\
$1 S N$ & Intermittent numbness, with or without tingling \\
$2 S N$ & $\begin{array}{l}\text { Intermittent or persistent numbness, reduced sen- } \\
\text { sory perception }\end{array}$ \\
$3 S N$ & $\begin{array}{l}\text { Intermittent or persistent numbness, reduced tac- } \\
\text { tile discrimination and/or manipulative dexterity }\end{array}$
\end{tabular}

a The sensorineural stage is to be established for each hand.

commonly in, and hence earlier in the development of, each Taylor-Pelmear stage of VWF.

A consistent staging of symptoms in individual cases can best be achieved by means of objective tests. For the present classification these tests will involve some measure of the integrity, sensitivity, or functional capacity of thermoreceptors, nociceptors, or mechanoreceptors in the fingers. Of these possibilities, recording degraded tactile sensation by measuring esthesiometer or vibrotactile perception thresholds has received the most attention, refined apparatus to control the stimulus entering the fingertip providing enhanced resolution $(3,16)$. In addition, determining the vibrotactile threshold over a broad range of frequencies will provide data on more than one mechanoreceptor type $(14,15)$ and, with appropriate conditions of stimulation, permit the sensitivity of each of the three receptor populations responsible for the sense of touch to be established (17). Substantial progress has also recently been made in quantifying the temperature sense, the magnitude of the neutral zone between warm and cool thresholds showing promise as an indicator of vibration-induced neuropathy (7). In contrast, studies of nerve conduction in vibration-exposed workers have produced conflicting results, though a recent analysis of these findings has revealed a common pattern of sensory nerve degeneration almost entirely confined to the hands (4).

Implicit in reliance on a single diagnostic test is its ability, in principle, to differentiate between each stage of, and hence reflect the development of most symptoms included in, the classification. This ability can only be verified by an evaluation of the performance of each apparatus and measurement procedure on vibration-exposed workers who have been medically examined to exclude unrelated disease and other confounding factors. Such a procedure is clearly time consuming. Furthermore, without a measure, direct or otherwise, of impaired hand function, it is difficult to assess the ability of an individual to perform his manual duties, which, although not explicitly included in the sensorineural classification, may ultimately be the basis for compensation. The close connection between tactile afferent activity and precise manipulation of small objects by the tips of the fingers and thumb suggests that quantifying some aspect of fine touch, either directly by esthesiometry or indirectly by vibro- 
tactile perception, could satisfy most requirements of a single sensory test (12).

The inherent limitations of a single diagnostic test can be overcome with two or more tests of peripheral function $(7,10)$. The potential for establishing the stage of VWF in individual cases by combining the results of traditional sensory tests has been discussed by Wasserman et al (21) and may be further explored with the use of the data in table 2. Despite the low percentage of normal responses in stage 3 cases (see table 2), Wasserman et al found that only $67 \%$ of workers in this stage possessed abnormal responses to all three stimuli, while the remaining $33 \%$ responded abnormally to two stimuli. Even less consistency was found in the combined results of the sensory tests for workers in earlier stages of the Taylor-Pelmear classification (namely, for stage 2: three normal responses - $13 \%$, one abnormal response $-13 \%$, two abnormal responses - $29 \%$, and three abnormal responses $45 \%$ ). The limited ability of the traditional neurological tests to separate individuals by stage, also noted elsewhere (19), suggests that other diagnostic tests are required. Confirmation of improved sensitivity and specificity by combining the results of up to 25 tests has been reported recently by Harada \& Matsumoto (11).

The addition of gap detection (ie, the ability of a fingertip to detect a groove of varying width in an otherwise flat surface), measured by an esthesiometer, to the sensory tests provides quantitative thresholds that

Table 4. Percentage of hands with normal responses to light touch, pain, and temperature and normal gap detection by sensorineural stage (data from references 3 and 19).

\begin{tabular}{lccccc}
\hline $\begin{array}{l}\text { Sensori- } \\
\text { neural } \\
\text { stage }^{a}\end{array}$ & $\begin{array}{c}\text { Number } \\
\text { of } \\
\text { hands }\end{array}$ & $\begin{array}{c}\text { Light } \\
\text { touch }\end{array}$ & $\begin{array}{c}\text { Pain } \\
\cdot\end{array}$ & $\begin{array}{c}\text { Temper- } \\
\text { ature }\end{array}$ & $\begin{array}{c}\text { Gap } \\
\text { detec- } \\
\text { tion }\end{array}$ \\
\hline 1SN & 9 & 100 & 78 & 67 & 100 \\
2SN & 37 & 43 & 19 & 5 & 81 \\
$3 S N$ & 90 & 10 & 0 & 0 & 0 \\
\hline
\end{tabular}

a Hands classified by the results of the sensory tests to be scored as follows: (i) zero when negative and one when positive - light touch, pain and temperature; and (ii) zero when normal and two when abnormal - gap detection, measured by an esthesiometer. Then stage 1SN = numbness + neurological score 0 or $1 ; 2 \mathrm{SN}=$ numbness + neurological score 2 or 3 ; and $3 S N=$ numbness + neurological score 4 or 5 .

Table 5. Ratings of the hands according to the TaylorPelmear and sensorineural classifications. The sensorineural classification has been made on the basis of objective tests (see table 4).

\begin{tabular}{|c|c|c|c|c|c|c|c|}
\hline \multicolumn{5}{|c|}{ Taylor-Pelmear stage } & \multicolumn{3}{|c|}{ Sensorineural stage } \\
\hline $0_{\mathrm{TN}}$ & 1 & 2 & 3 & 4 & $1 \mathrm{SN}$ & $2 \mathrm{SN}$ & $3 \mathrm{SN}$ \\
\hline 4 & 6 & 38 & 82 & 6 & $\begin{array}{l}1 \\
3 \\
5 \\
0 \\
0\end{array}$ & $\begin{array}{r}1 \\
2 \\
22 \\
12 \\
0\end{array}$ & $\begin{array}{r}2 \\
1 \\
11 \\
70 \\
6\end{array}$ \\
\hline
\end{tabular}

may be assessed against a population norm, in the present discussion derived from manual workers unexposed to vibration (3). This test (which is equivalent to Weber two-point discrimination) was selected because of the availability of data for further analysis from individuals in group $b$, its ability to record reduced tactile (spatial) discrimination, a requirement of stage 3SN, and its correlation with hand function as determined by the Moberg pick-up test (6).

If the results of these four tests are now assigned a numerical score, which may also reflect the confidence in each, it is possible to classify individuals by sensorineural stage based on the combined (total) score. One such scheme has been applied to the data from source $b$ in table 4 . It is based on scoring responses to the traditional neurological tests as zero when normal and as one when abnormal, and the gap detection threshold being given the score of zero when normal and two when abnormal. The combined score, as well as reports of finger numbness, is then used to stage individuals as indicated in the footnote to the table.

It is evident from table 4 that the basic description of each proposed sensorineural stage is well reflected in these data from 136 hands, reduced tactile spatial discrimination occurring in $100 \%$ of the hands in stage $3 \mathrm{SN}$, yet significantly reduced sensory perception but normal tactile discrimination occurring in a large majority of the hands in stage $2 \mathrm{SN}$. A reduction in sensory perception is uncommon in stage $1 \mathrm{SN}$, though one-third of the hands responded abnormally to the thermal stimulus. The reason for this somewhat unexpected result is unclear, though it may reflect more the inadequacy of the measurement procedure than thermoreceptor dysfunction.

A comparison between the original Taylor-Pelmear classification of the hands in table 4 and their sensorineural stages is given in table 5 . While hands in the most severe stages ( 3 and 4 ) according to the TaylorPelmear classification are commonly reclassified as stage 3SN (76/88 hands), this numerical correspondence between classifications is not so evident in the earlier stages. Close inspection of table 5 reveals that the Taylor-Pelmear stage considered to precede those involving vasospasms (stage $0_{\mathrm{TN}}$ ) includes persons with all stages of sensorineural disturbances (ie, stages $1 \mathrm{SN}$ to $3 \mathrm{SN}$ ). This observation confirms the need for a separate assessment of the vascular and neurological components of the syndrome for each hand.

\section{Conclusions}

A classification of the peripheral neurological symptoms dominated by sensory afferent involvement has been proposed for the hand-arm vibration syndrome. Three symptomatic stages have been defined for vibration-exposed persons without reference to peripheral vascular dysfunction, based on the results of objective sensory tests on 634 hands. The first stage con- 
sists essentially of episodic finger numbness (1SN), the second involves, in addition, reduced sensory perception (2SN), while the most severe stage focuses on reduced tactile discrimination and/or manipulative dexterity (3SN).

It appears that the sensory tests traditionally employed by neurologists (fine touch, pain, and temperature) need to be augmented with one (or more) precise, quantitative measure of peripheral somatosensory dysfunction in order to implement consistently the sensorineural classification. A procedure for staging individual hands may then be based on a combination of numerical scores assigned to each test result.

\section{References}

1. Banister PA, Smith FV. Vibration-induced white finger and manipulative dexterity. Br J Ind Med 29 (1972) 264-267.

2. Bleecker ML. Vibration perception thresholds in entrapment and toxic neuropathies. J Occup Med 28 (1986) $991-994$.

3. Brammer AJ, Piercy JE, Auger PL. Assessment of impaired tactile sensation: A pilot study. Scand J Work Environ Health 13 (1987) 380-384.

4. Brammer AJ, Pyykkö I. Vibration-induced neuropathy: Detection by nerve conduction measurements. Scand J Work Environ Health 13 (1987) 317-322.

5. Brammer AJ, Taylor W, Piercy JE. Assessing the severity of the neurological component of the hand-arm vibration syndrome. Scand J Work Environ Health 12 (1986) $428-431$.

6. Dellon AL. Evaluation of sensibility and re-education of sensation in the hand. Williams and Wilkins, Baltimore, MD 1981.

7. Ekenvall L, Nilsson BY, Gustavsson P. Temperature and vibration thresholds in vibration syndrome. $\mathrm{Br} \mathrm{J}$ Ind Med 43 (1986) 825-829.

8. Gemne G, Pyykkö I, Taylor W, Pelmear PL. The Stockholm Workshop scale for the classification of cold-induced Raynaud's phenomenon in the hand-arm vibration syndrome (revision of the Taylor-Pelmear scale). Scand J Work Environ Health 13 (1987) 275-278.

9. Gemne G, Taylor W, ed. Hand-arm vibration and the central autonomic nervous system. J Low Freq Noise Vib 1 (1983): special issue.
10. Harada N, Matsumoto T. Various function tests on the upper extremities and the vibration syndrome. In: Brammer AJ, Taylor W, ed. Vibration effects on the hand and arm in industry. John Wiley \& Sons, New York, NY 1982, pp 71-76.

11. Harada N, Matsumoto $T$. Validity of various function tests performed in Japan as a screening test for vibration syndrome. Int Arch Occup Environ Health 54 (1984) 283-293.

12. Johansson RS, Westling G. Roles of glabrous skin receptors and sensorimotor memory in automatic control of precision grip when lifting rougher or more slippery objects. Exp Brain Res 56 (1984) 550-564.

13. Juntunen J, Matikainen E, Seppäläinen AM, Laine A. Peripheral neuropathy and vibration syndrome. Int Arch Occup Environ Health 52 (1983) 17-24.

14. Löfvenberg J, Johansson RS. Regional differences and interindividual variability in sensitivity to vibration in the glabrous skin of the human hand. Brain Res 301 (1984) $65-72$.

15. Lundborg G, Lie-Stenström AK, Sollerman C, Strömberg T, Pyykkö I. Digital vibrogram: A new diagnostic tool for sensory testing in compression neuropathy. J Hand Surg 11A (1986) 693-699.

16. Lundborg G, Sollerman C, Strömberg T, Pyykkö I, Rosén $B$. A new principle for assessing vibrotactile sense in vibration-induced neuropathy. Scand J Work Environ Health 13 (1987) 375-379.

17. Piercy JE, Brammer AJ. Development of vibrotactile measurement techniques for assessing mechanoreceptor performance at the fingertip. J Acoust Soc Am 80 (1986): suppl 1, S41.

18. Pyykkö I, Korhonen OS, Färkkilä MA, Starck JP, Aatola SA. A longitudinal study of the vibration syndrome in Finnish forestry workers. In: Brammer AJ, Taylor $\mathrm{W}$, ed. Vibration effects on the hand and arm in industry. John Wiley \& Sons, New York, NY 1982, pp $157-167$

19. Taylor W, Ogston SA, Brammer AJ. A clinical assessment of seventy-eight cases of hand-arm vibration syndrome. Scand J Work Environ Health 12 (1986) $265-268$.

20. Taylor W, Pelmear PL, ed. Vibration white finger in industry. Academic Press, London 1975, pp xvii-xxii.

21. Wasserman D, Taylor W, Behrens V, Samueloff S, Reynolds D. Vibration white finger disease in US workers using pneumatic chipping and grinding hand tools: I Epidemiology. US Department of Health and Human Services, Cincinnati, OH 1982. (DHHS (NIOSH) publication no $82-118)$. 